\title{
Dynamic Status Signal Reflects Outcome of Social Interactions, but Not Energetic Stress
}

\author{
Keith A. Tarvin ${ }^{1 *}$, L. Jin Wong ${ }^{1}$, David C. Lumpkin ${ }^{1}$, Gabrielle M. Schroeder ${ }^{1}$, \\ Dominic D'Andrea ${ }^{1}$, Sophie Meade ${ }^{1}$, Pearl Rivers ${ }^{1}$ and Troy G. Murphy ${ }^{2}$
}

${ }^{1}$ Department of Biology, Oberlin College, Oberlin, OH USA, ${ }^{2}$ Department of Biology, Trinity University, San Antonio, TX, USA

\section{OPEN ACCESS}

Edited by:

Geoffrey E. Hill,

Auburn University, USA

Reviewed by:

Fernando Mateos-Gonzalez, University of Konstanz, Germany

Lynn Marie Siefferman,

Appalachian State University, USA

*Correspondence:

Keith A. Tarvin

keith.tarvin@oberlin.edu

Specialty section:

This article was submitted to Behavioral and Evolutionary Ecology,

a section of the journal

Frontiers in Ecology and Evolution

Received: 09 April 2016 Accepted: 13 June 2016 Published: 27 June 2016

Citation: Tarvin KA, Wong LJ, Lumpkin DC, Schroeder GM, D'Andrea $D$, Meade S, Rivers $P$ and Murphy TG (2016) Dynamic Status Signal Reflects Outcome of Social Interactions, but

Not Energetic Stress.

Front. Ecol. Evol. 4:79.

doi: 10.3389/fevo.2016.00079
Social defeat induces stress-responses in a wide array of vertebrates and can generate winner-loser effects. Dynamic condition-dependent signaling systems that reflect preparation for subsequent agonistic interactions, and thereby mediate winner-loser effects, should be more sensitive to competitive history than to non-social sources of stress. Bill color of female American goldfinches (Spinus tristus) is a dynamic condition-dependent ornament that functions as a signal of competitive status and mediates intrasexual agonistic social interactions. We tested the "social experience signaling hypothesis" in female goldfinches by (1) manipulating a non-social energetic stressor by experimentally elevating flight costs via wing-clipping in free-ranging birds, and (2) manipulating social experience by staging competitive interactions among captive birds. Bill color change did not differ between wing clipped and non-clipped females, even though stress-response, as measured by the heterophil to lymphocyte $(\mathrm{H}: \mathrm{L})$ ratio, increased significantly in clipped females relative to unclipped females. In contrast, winners and losers in the social experience experiment differed significantly in the degree and direction of bill color change following social contests, with bill color increasing in winners and decreasing in losers. These results suggest that dynamic bill color of female American goldfinches signals recent social history, but is less sensitive to some stressors stemming from non-social sources, and thereby suggest that signals can evolve sensitivity to specific types of processes relevant to the context in which they are used.

Keywords: social experience, stress, condition-dependent dynamic signal, bill color, American goldfinch, female ornamentation, status signal, Spinus tristis

\section{INTRODUCTION}

Ornaments that reliably signal condition are important mediators of social interactions, including mate choice, offspring provisioning, and social competition (Lyon and Montgomerie, 2012). Dynamic condition-dependent ornaments have the capacity to signal recent changes in condition (i.e., the "relative capacity to maintain optimal functionality of vital systems within the body;" Hill, 2011), and therefore may provide information about current conditional state with very short time lags (Sullivan, 1994a,b; Torres and Velando, 2003; Velando et al., 2006; Bamford et al., 2010; Rosenthal et al., 2012). Because dynamic condition-dependent signals can be particularly informative regarding short-term changes in condition, they may be especially important during competitive social interactions because competitive ability or motivation may covary with current physiological state. 
Dynamic condition-dependent signals may reflect various aspects of condition, such as nutritional state, immunocompetence, or recent exposure to stressors (Faivre et al., 2003; Velando et al., 2006; Pérez-Rodriguez, 2008; Ardia et al., 2010; Navarro et al., 2010; Rosenthal et al., 2012). Stressresponses may result from physiological challenges such as nutritional deficiencies, infection, physical trauma, or changing abiotic conditions (e.g., Hill, 2014; Schulte, 2014), but they also can be elicited by psychological phenomena such as perceived predation risk and competitive social interactions (Buchanan, 2000; Creel et al., 2013; Wingfield, 2013). For example, many studies have shown that social defeat, in which an individual loses a competitive contest with a rival, induces a wide variety of both transient and persistent detrimental and compensatory physiological changes consistent with stress-responses in a variety of vertebrates (see Buwalda et al., 2005; Hostetler and Ryabinin, 2013 for general reviews), including birds (e.g., Zuk and Johnsen, 2000; Carere et al., 2001, 2003; Gleeson, 2006; Hawley, 2006; Hawley et al., 2006). Different sources and kinds of stressors can yield dramatically different physiological responses, involving a variety of pathways, neurotransmitters, and target tissues (Buchanan, 2000; Armario et al., 2012; Hostetler and Ryabinin, 2013). Therefore, it is possible that stress-responses resulting from social interactions may manifest differently than stress-responses derived from other sources, in which case certain dynamic signals could be influenced more by social experience than by other physiological perturbations.

In a handful of species, intraspecific social interactions have been shown to affect future expression of dynamic conditiondependent ornaments (mandrills, Mandrillus sphinx: Setchell and Dixson, 2001; red jungle fowl, Gallus gallus: Zuk and Johnsen, 2000, Cornwallis and Birkhead, 2008; pukeko, Porphyrio porphyria: Dey et al., 2014; zebra finches, Taeniopygia guttata: Gleeson, 2006; red-backed fairy-wrens Malurus melanocephalus: Karubian et al., 2011; green swordtails, Xiphophorus helleri: Rhodes and Schlupp, 2012). Although it is clear that social interactions can influence both stress-responses and dynamic signal expression, it remains unexplored whether dynamic signals that function to mediate social interactions primarily reflect social experience, or whether social experience is but one example of a more general class of stressors to which they respond.

Orange bill color of female American goldfinches (Spinus tristis, henceforth goldfinch) is a dynamic condition-dependent ornament (Kelly et al., 2012; Rosenthal et al., 2012) that mediates competitive interactions among female goldfinches (Murphy et al., 2009, 2014). Several studies have demonstrated that the seasonal development of goldfinch bill color prior to the breeding season is influenced by dietary carotenoid intake (McGraw and Hill, 2000, 2001; Hill et al., 2009; all of these studies focused on male goldfinches) and testosterone (in both sexes; Mundinger, 1972). Furthermore, instantaneous "snapshot" measures of female bill color during the breeding season are correlated with measures of immunocompetence, recent stressresponse as indexed by the heterophil to lymphocyte $(\mathrm{H}: \mathrm{L})$ ratio, and circulating testosterone (Kelly et al., 2012; Pham et al., 2014). The dynamic component of goldfinch bill color also reflects condition: bill color of both males and females declines within hours after free-ranging birds are brought into captivity and continues to decline for several days, and experimental immune challenge enhances the decline (Rosen and Tarvin, 2006; Rosenthal et al., 2012). Although the seasonal development of bill color is influenced by intestinal parasite infection (McGraw and Hill, 2000), "snapshot" measures of bill color of freeranging goldfinches during the breeding season do not reflect current trypanosome infection status, even though plumage color strongly predicts infection during that period (Lumpkin et al., 2014). Although at first pass it appears that bill color reflects a wide array of stressors, studies of short-term changes in bill color have been conducted on captive birds (Rosen and Tarvin, 2006; Rosenthal et al., 2012), leaving open the possibility that observed changes in bill color may have reflected either adverse social conditions or more general non-social sources of stress.

In this study we test the hypothesis that bill color of female goldfinches changes in response to competitive social interactions but not in response to more generalized non-social physiological stressors. This "social experience signaling" hypothesis stems from work indicating that winner and loser effects (Landau, $1951 a, b)$ can increase fitness for both winners and losers in social groups (Dugatkin and Reeve, 2014). Thus, expression of a dynamic signal of status tied to a competitor's past history (see Rutte et al., 2006) could allow superior competitors to use their signals to preemptively avoid unnecessary costly exertion of dominance during agonistic interactions, while also allowing inferior competitors to avoid wasting time and energy and incurring risk of physical harm from battling in light of a foregone conclusion (sensu Rohwer, 1975). Moreover, recent work suggests that we might expect a dynamic signal that mediates competitive interactions to be affected by those very interactions (Dey et al., 2014), given that hormonally mediated signal expression can alter physiological state via social feedback (Rubenstein and Hauber, 2008; Safran et al., 2008; Vitousek et al., 2014). Because dynamic bill color of female goldfinches appears to function exclusively to mediate competitive social interactions with other female goldfinches (Murphy et al., 2009, 2014), it seems reasonable to expect that it may have evolved to dynamically signal an individual's competitive history.

The social experience signaling hypothesis predicts that bill color should decline in response to social defeat, but not in response to a short-term elevation of a physiological stressor that is administered outside of the context of social interactions. Although a signal that responds to general physiological stressors can provide information to receivers about general condition, a dynamic ornament that specifically signals recent social experience can provide reliable information about winner or loser effects. Thus, a dynamic signal linked to previous competitive success can signal information about the likelihood of future escalation and thus an individual's current ability to win an interaction. We tested these hypotheses with two separate experiments. In the first experiment we manipulated a non-social energetic stressor in free-ranging goldfinches by trimming the tips of primary feathers to reduce wingspan, thus elevating flight costs. This technique has been used successfully to elevate flight costs in other studies (e.g., Mauck and Grubb, 1995; Carrascal and Polo, 2006; Tieleman et al., 2008). We compared changes 
in bill color between manipulated and unmanipulated birds 1-3 weeks following the treatment. In a second experiment we staged competitive interactions among pairs of goldfinches over a 2-day period and compared changes in bill color before and after social competition between dominant (i.e., winners) and subordinate birds (i.e., losers).

\section{METHODS}

\section{General}

We manipulated the magnitude of an energetic stressor and social experience in separate experiments to test their effects on bill color change. Both experiments were conducted after migration and seasonal development of bill color (from gray to orange) was complete, but before the onset of nesting. In each experiment, we measured bill color with an Ocean Optics USB4000 spectrometer and a PX2 xenon strobe lamp (Ocean Optics, Dunedin, FL USA) using a probe with a $3 \mathrm{~mm}$ aperture held $5 \mathrm{~mm}$ from the bill. Each bill color sample was made by taking 4 replicate measures on the right side of the bill $\sim 1 \mathrm{~mm}$ anterior to the nares with the probe held at a $90^{\circ}$ angle. We calibrated the spectrometer using a Spectralon white standard and a dark standard before and after each set of replicate measures. We used CLR version 1.05 and RCLR version 0.9.28 (Montgomerie, 2008a,b) to calculate bill brightness as the mean percent reflectance across the avian visible-spectrum (320-700 nm, in $1 \mathrm{~nm}$ increments), yellow saturation as the sum of percent reflectance between 550 and $635 \mathrm{~nm}$ divided by the sum of percent reflectance across the entire avian-visible spectrum, and hue as the wavelength (in $\mathrm{nm}$ ) corresponding to the midpoint of the highest and lowest reflectance values.

All statistical analyses were conducted with IBM SPSS Statistics version 21 (Armonk, NY, USA). We tested all relevant variables for normality with Kolmogorov-Smirnov tests.

\section{Energetic Stressor Experiment}

We captured goldfinches at Carlisle Reservation, Lorain County Metro Parks, OH USA $\left(41^{\circ} 17^{\prime} 22.33^{\prime \prime} \mathrm{N}, 82^{\circ} 9^{\prime} 49.63^{\prime \prime} \mathrm{W}\right)$ from 07 June to 02 July 2010, and from 06 June to 06 July 2011 in mist nets and basket traps at feeders (see Lumpkin et al., 2014 for details). We captured 3 additional birds at a second field site $\sim 17 \mathrm{~km}$ distant during this same period (late June, 2011).

To increase energetic stress, we elevated flight costs by trimming the tips of three to four outer primary feathers so as to reduce the wing span by $\sim 7 \%$. We used Pennycuick's (2008a,b) Flight for Windows program to estimate the effect of wing clipping on flight costs on a sample of eight female goldfinch specimens collected during earlier studies. We measured wingspan of the specimens to the nearest $\mathrm{mm}$ and traced the fully extended right wing on $0.5 \mathrm{~cm}$ gridded paper to estimate wing area. We then trimmed $3.5 \%$ of the wingspan from the distal tip of the right folded wing with scissors, and traced the manipulated wing to estimate the modified wing area. In most cases, the clipping procedure removed the tips of primaries 7-9 but left other primaries and secondaries intact; occasionally the tip of primary 6 also was removed. We used the mean mass of live female goldfinches captured in our study to calculate the change in flight costs for female goldfinches at the altitude of our field site $(\sim 66 \mathrm{~m})$ to account for air density. Averaged over the 8 specimens, we estimate that, following our treatment, the rate of fuel energy consumption when flying level at minimum power velocity $\left(\mathrm{V}_{\mathrm{mp}}\right)$ would increase from 0.779 to $0.927 \mathrm{~W}$, and that when flying at maximum range velocity $\left(\mathrm{V}_{\mathrm{mr}}\right)$ it would increase from 1.027 to $1.225 \mathrm{~W}$ (i.e., increases of 19.0 and $19.3 \%$ respectively). Female goldfinches spend much time flying long distances to forage at widely scattered and temporally ephemeral food patches prior to the onset of nesting, and therefore our manipulation is likely to have impacted their daily energetic expenditure.

In the field, the first bird that was captured was randomly allocated to the clipped or unclipped (control) treatment; thereafter, we alternated the treatment for birds captured subsequently. At first capture for an individual goldfinch, we measured bill color immediately after capture (mean \pm s.e. $=22$ $\pm 2.4 \mathrm{~min}$; $\max 95 \mathrm{~min}$ ), collected a blood sample (see below), banded the bird with a uniquely numbered metal leg band, and measured the outstretched wing to the nearest $\mathrm{mm}$ from the root to the primary feather exhibiting the greatest projection. We then calculated the length that represented $7 \%$ of the intact wing and clipped the primaries as described above. For our control birds, we conducted the same measures, collected a blood sample, held the birds for the same length of time, and held scissors near the wing to mimic the manipulation. All birds were released following the manipulation. We recaptured birds $1-3$ weeks later (mean $12 \mathrm{~d}$, s.e. $1.07 \mathrm{~d}$, range 7-22 d) and again measured bill color, collected a blood sample, and released the birds. In total, we captured 133 individual female goldfinches for this experiment, and were able to recapture 23 of them 1-3 weeks after the initial capture for use in the analysis. We also captured 150 males (51 were recaptured) and treated them in the same manner (see Supplemental Material).

We tested whether the wing clipping procedure led to increased physiological stress-response using the ratio of heterophils to lymphocytes (H:L ratio) in blood smears. The $\mathrm{H}: \mathrm{L}$ ratio reflects recent stress-response because glucocorticoids increase the production of heterophils and decrease the production of lymphocytes (Davis et al., 2008); thus, higher H:L ratios indicate higher stress-response. We collected $\sim 20-100 \mu \mathrm{L}$ of blood from the brachial vein and made two blood smears on microscope slides which were air dried and stained with 3 Step Stain Set (Richard-Allan Scientific, Kalamazoo, MI, USA) or Harleco Hemacolor ${ }^{\circledR}$ (EMD Chemicals, Inc., Gibbstown, NJ, USA). For each sample, we scanned the smear with the most uniform monolayer of cells at $100 \times$ until we had identified 100 leukocytes, and used data from that smear for analysis.

We measured the change in each tristimulus bill color variable as the color value at capture 2 minus that at capture 1 . Similarly, we measured the change in $\mathrm{H}: \mathrm{L}$ ratio between captures as the $\mathrm{H}: \mathrm{L}$ ratio at capture 2 minus the $\mathrm{H}: \mathrm{L}$ ratio at capture 1 . We evaluated the change in bill color (tristimulus values analyzed separately) and $\mathrm{H}: \mathrm{L}$ ratio using generalized linear models with a linear response distribution and identity link function, with treatment (clipped or not clipped) as a factor, and used the following as covariates: timespan in days between first and second capture, 
the interaction between treatment and timespan (to account for temporal effects of the treatment), and the initial value of the dependent variable under consideration (to account for variation in initial state among individuals due to capture date, etc.).

\section{Social Experience Experiment}

We captured goldfinches at several sites within Lorain County, $\mathrm{OH}$ during June 2013 and brought them into animal care facilities at Oberlin College. We staged pair-wise agonistic contests between focal and stimulus (competitor) females and compared bill color change in focal birds that were dominant to their partners with bill color change in focal birds that were subordinate to their partners.

Females were caught in groups of 6-9 birds per day (a cohort) on 18,20,22, 24, 27, and 28 June 2013 and brought into captivity; all members of a given cohort were on a common schedule once in captivity. Birds captured on 18 and 20 June were combined into a single cohort and randomly assigned to be focal or stimulus birds. Thereafter, focal birds from a cohort were used as stimulus birds for the subsequent cohort. When we captured more individuals than needed for a cohort, we used the six individuals that best matched the stimulus birds that were already designated to be used for that cohort (see below), and used the extra birds for other experiments or released them. Experimental pairs comprised individual birds captured from sites at least $8 \mathrm{~km}$ apart and so were unlikely to have encountered each other prior to their social trial. Focal birds in each of the five cohorts and the stimulus birds used for Cohort 1 were maintained for $5-9$ days $($ mean $=7.87 \mathrm{~d}$ ) in individual cages separated by opaque partitions such that they could not see other individuals prior to social trials (birds in Cohort 1 were held captive for 5 days prior to trials; those in Cohorts 2-4 were held for 9 days; in Cohort 5, four individuals were held for 7 days and two were held for 8 days prior to the trial). Two days before the social trials for a given cohort, we measured bill color and weighed the focal birds, and placed a single metal USFWS band on the leg opposite to the banded leg of the stimulus bird with which they would be paired and returned them to their cages; they otherwise were not handled prior to the day of the social trial. On the morning of a trial, each focal bird and a stimulus bird were matched into a dyad based on similarity in mass and bill color (based on a visual comparison of bill color). To conduct the trial, the dyad of females was placed into a cage in an experimental room that was separate from the housing room. Dyads were visually isolated from other dyads with opaque partitions, although the front of each cage was open to the room so that we could video-record interactions. Each experimental cage had a single food dish at the lower front center of the cage, a "low perch" that ran parallel to the front of the cage and provided access to the food dish, a smaller "high perch" near the top of the cage near the back, and a water dispenser placed in the middle of one side of the cage (Figure 1). The cage was designed to allow monopolization of resources and space: only a single bird could feed, drink, or occupy the high perch at a given time. Focal birds remained with stimulus birds in the experimental cage for $\sim 26 \mathrm{~h}$ (from $\sim 08: 30$ of day 1 of the trial through $\sim 10: 30$ of day 2 of the trial), at which time they were removed to their individual cages in the housing room.

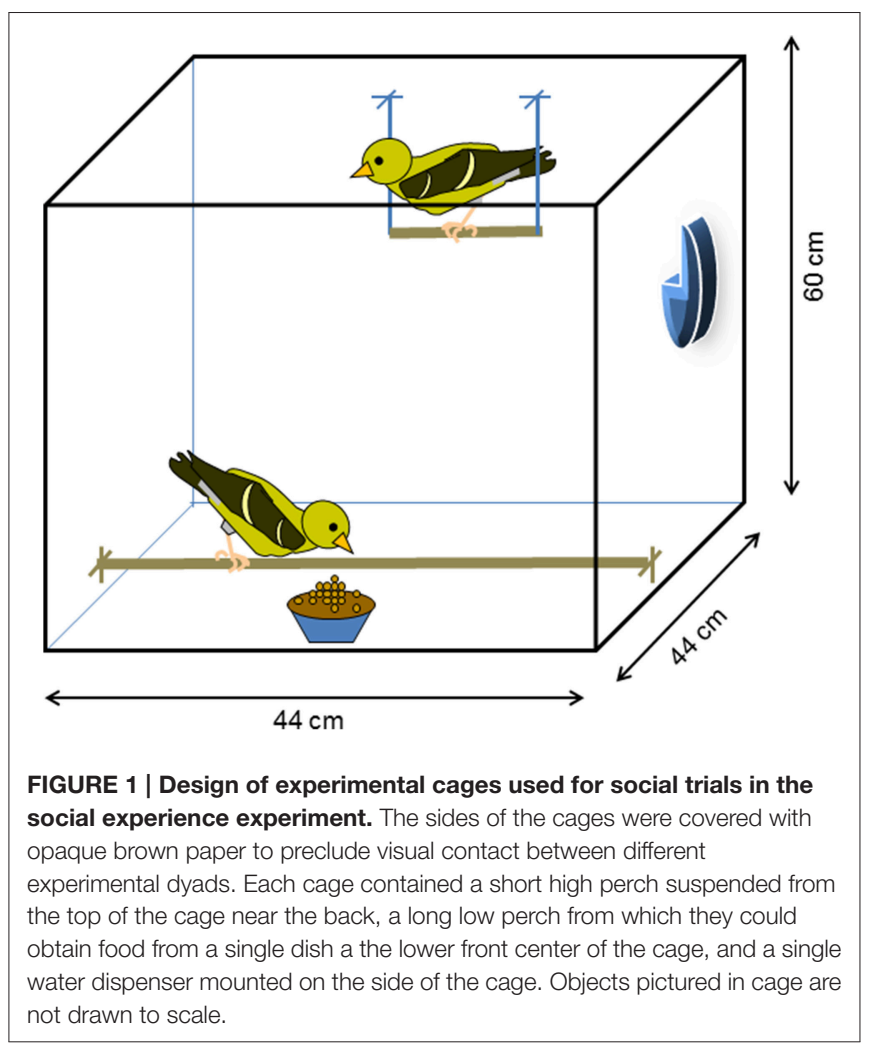

For cohort 1, we again measured bill color, weighed each focal bird, and collected a blood sample 4 days after the conclusion of the social trial. For the remaining cohorts, we conducted these procedures $\sim 4 \mathrm{~h}$ after the conclusion of the social trials. We changed the schedule of the protocol following cohort 1 because an interruption in field work necessitated that we reduce the time-span between remaining cohorts in order to complete trials for all five cohorts before the onset of nesting, when female bill color begins to decline. All birds were released at their original capture site $\sim 1$ week after serving as a stimulus bird.

We video-recorded social interactions for $60 \mathrm{~min}$ at three different points during trials to assess whether focal birds were dominant or subordinate to the stimulus birds with which they were paired. We sampled behavior from the first recording $\sim 60$ min after the two birds were placed in the experimental cage and researchers had left the experimental room (09:30). The second video began at $\sim 15: 00$ on the same day, and the third video began at $\sim 08: 30$ on the second day of the trial. Because we had to enter the room to turn on the video cameras during the second and third recordings, we allowed a 5 min acclimation period after we left the room to pass before the scoring period began. During each video recording, we quantified the number of times each bird supplanted the other, the number of times each bird chased the other, and the number of times each bird lunged at or bill-fenced at the other, following Ardia et al. (2010) (see also Coutlee, 1967). For analyses, we simply tallied the total number of aggressive interactions initiated by each bird during the observation periods. We defined winners as those birds that initiated more aggressive interactions than their partners. On average, the 16 focal winners 
initiated 61.9 (s.e. $=15.2$ ) more interactions than their partners, whereas the 14 focal losers initiated 49.7 (s.e. $=17.2$ ) fewer aggressive interactions than their partners $(t=4.876, d f=28$, $P<0.0001)$.

We calculated the change in bill color over time as the difference in a tristimulus variable measured before and after social trials (i.e., bill color following completion of the trial minus bill color 2 days before the onset of the trial). We tested the effect of social competition on the change in bill color by comparing the change in color of dominant vs. subordinate focal birds using generalized linear models with social fate (dominant vs. subordinate) and cohort as factors and the initial pre-trial bill color tristimulus value as a covariate to account for individual variation in bill color prior to the onset of trials (see Rosenthal et al., 2012; Dey et al., 2014). Each tristimulus variable was analyzed separately.

Because we detected statistically significant changes in bill color tristimulus values in response to social competition (see Results), we tested whether the magnitude of bill color change was likely to be detectable by receivers based on chromatic distance $(\Delta S$; Vorobyev et al., 1998) and achromatic distance ( $\Delta L$; Siddiqi et al., 2004), measured in units of "just noticeable differences" (JND; Vorobyev et al., 1998). A difference of 1.0 JND is considered to reflect a detectable change in color or brightness (Vorobyev et al., 1998; Siddiqi et al., 2004). We used the program pavo in R (Maia et al., 2013) to calculate $\Delta S$ and $\Delta L$ within dominants before and after trials, and within subordinates before and after trials. We calculated $\Delta S$ and $\Delta L$ across the avian visual spectrum (320-700 $\mathrm{nm}$ ) using an American goldfinch visual model (Baumhardt et al., 2014), assuming a standard daylight illuminant ("D65" in pavo) and an idealized homogeneous background based on formulae presented in Vorobyev et al. (1998) and Siddiqi et al. (2004) as executed in pavo (Maia et al., 2013).

We tested whether social interactions differentially affected stress-response in winners vs. losers by measuring $\mathrm{H}$ :L ratio from the blood samples collected following the conclusion of social trials. We compared H:L ratio between winners and losers with a generalized linear model with a linear response distribution and identity link function and with cohort and social fate as factors. We did not measure the change in $\mathrm{H}: \mathrm{L}$ ratio before and after social trials in order to avoid bleeding birds prior to trials, which would have increased the stress-response.

\section{Direct Comparison of Magnitude of Color Change between the Two Experiments}

We directly compared the magnitude of bill color change observed in the two experiments with a single generalized linear model with change in the tristimulus variable as the response variable and treatment group (clipped, unclipped, dominant, subordinate) as a factor; we included the initial value of the color parameter and the timespan between measures as covariates.

The use of animals in this study was approved by the Oberlin College Institutional Animal Care and Use Committee (\#S10RBKT-13, \#S13RBKT-1), and was covered by USFWS Bird
Banding Permit 23065, USFWS Scientific Collecting Permit MB044805 and Ohio Department of Natural Resources Scientific Collecting Permit 14-214.

\section{RESULTS}

\section{Effect of Energetic Stressor vs. Social Experience on Bill Color}

In the Energetic Stressor experiment, the wing-clip treatment did not affect the change in bill color between the first and second captures (Table 1). Clipped birds $(n=11)$ did not differ from control birds $(n=12)$ in the change in bill brightness (likelihood ratio $\chi^{2}=2.689, d f=1, P=0.101$ ), yellow saturation (likelihood ratio $\chi^{2}=2.079, d f=1, P=0.149$ ), or hue (likelihood ratio $\chi^{2}=0.435, d f=1, P=0.510$; Figure 2) when controlling for timespan, the interaction between treatment and timespan, and the initial value of the dependent variable. Likewise, the interaction between treatment and timespan did not influence the change in bill brightness (likelihood ratio $\chi^{2}=2.494$, $d f=1, P=0.114$ ) or hue (likelihood ratio $\chi^{2}=0.606$, $d f=1, P=0.436$ ), although this interaction indicated a marginal but non-significant effect on yellow saturation (likelihood ratio $\chi^{2}=3.471, d f=1, P=0.062$ ). These results were qualitatively unchanged when we included year as a factor or omitted the

TABLE 1 | Results of generalized linear models testing for change in bill color and H:L ratio in response to wing clipping in the Energetic Stressor experiment.

\begin{tabular}{|c|c|c|c|c|}
\hline $\begin{array}{l}\text { Response } \\
\text { variable }\end{array}$ & Predictor variable & $\begin{array}{l}\text { Likelihood } \\
\text { ratio } \chi^{2}\end{array}$ & $d f$ & $P$ \\
\hline \multirow[t]{5}{*}{ Brightness } & Wing clip & 2.689 & 1 & 0.101 \\
\hline & Timespan & 8.128 & 1 & 0.004 \\
\hline & Clip $\times$ timespan & 2.494 & 1 & 0.114 \\
\hline & Initial brightness & 10.821 & 1 & 0.001 \\
\hline & Intercept & 2.258 & 1 & 0.133 \\
\hline \multirow[t]{5}{*}{ Yellow saturation } & Wing clip & 2.079 & 1 & 0.149 \\
\hline & Timespan & 7.066 & 1 & 0.008 \\
\hline & Clip $\times$ timespan & 3.471 & 1 & 0.062 \\
\hline & Initial saturation & 12.848 & 1 & $<0.0004$ \\
\hline & Intercept & 10.290 & 1 & 0.001 \\
\hline \multirow[t]{5}{*}{ Hue } & Wing clip & 0.435 & 1 & 0.510 \\
\hline & Timespan & 0.504 & 1 & 0.478 \\
\hline & Clip $\times$ timespan & 0.606 & 1 & 0.436 \\
\hline & Initial hue & 13.206 & 1 & $<0.0003$ \\
\hline & Intercept & 8.713 & 1 & 0.003 \\
\hline \multirow[t]{5}{*}{$\mathrm{H}: \mathrm{L}$ ratio } & Wing clip & 13.969 & 1 & $<0.0002$ \\
\hline & Timespan & 3.639 & 1 & 0.056 \\
\hline & Clip $\times$ timespan $^{\mathrm{a}}$ & 12.739 & 1 & $<0.0004$ \\
\hline & Initial H:L ratio & 18.423 & 1 & $<0.0001$ \\
\hline & Intercept & 2.061 & 1 & 0.151 \\
\hline
\end{tabular}

${ }^{a} H: L$ ratio of clipped females increased when timespan between captures was relatively short, but not when timespan was long (see Figure S1). 
A

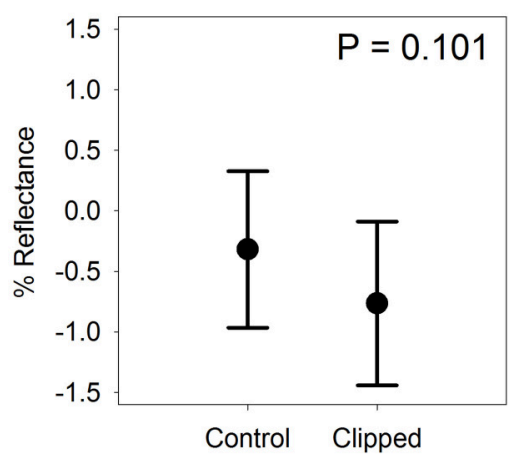

Energetic Status
B Change in Yellow Saturation

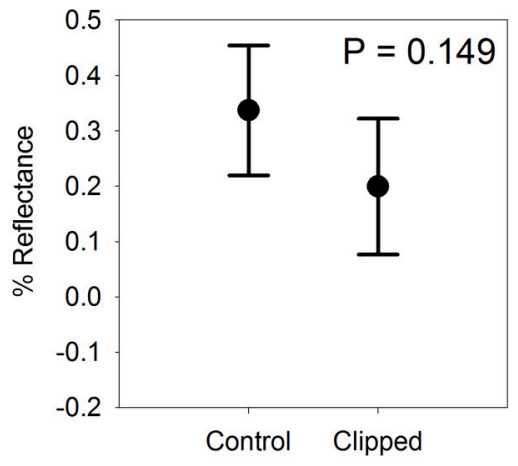

Energetic Status c Change in Hue

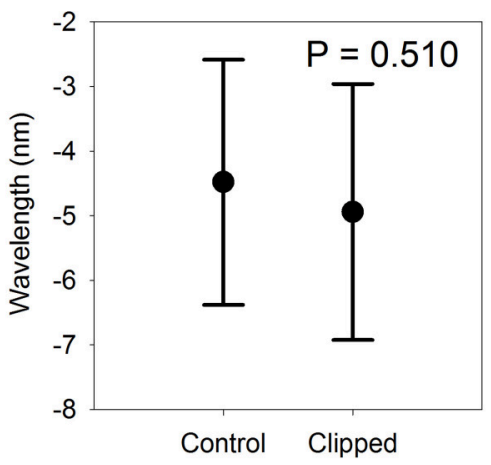

Energetic Status
D

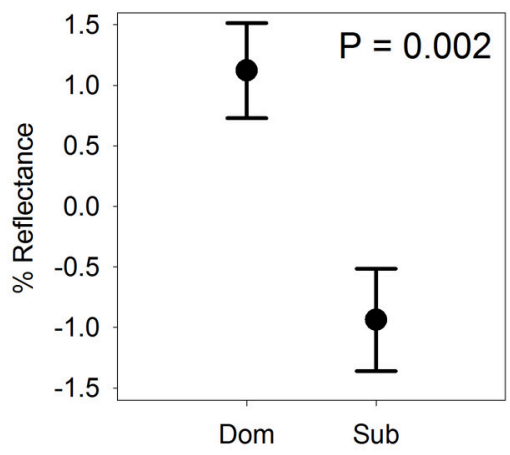

Social Status
E Change in Yellow Saturation

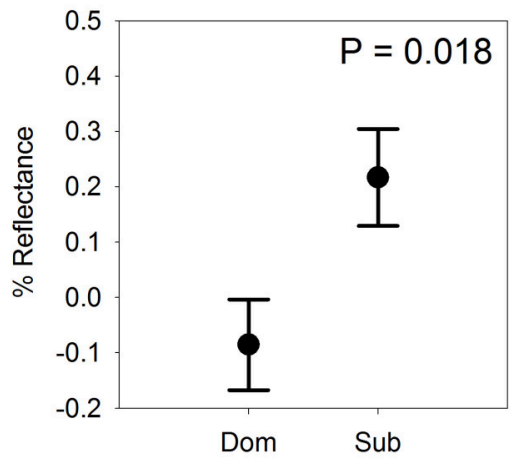

Social Status
$\mathbf{F} \quad$ Change in Hue

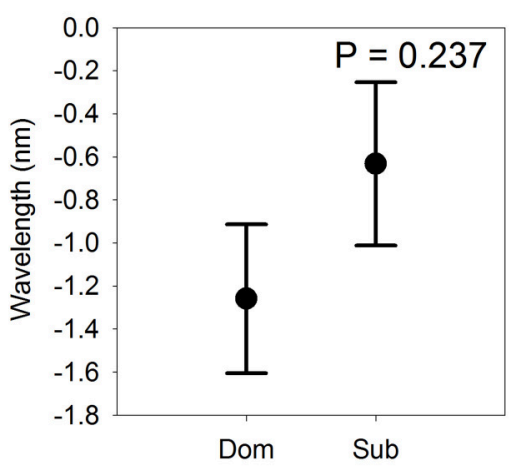

Social Status

FIGURE 2 | Bill color change of female American goldfinches in response to elevation of an energetic stressor (A-C) and recent competitive experience (D-F). Means and standard errors in the top panels are adjusted for effects of the timespan between captures, the interaction between timespan and treatment, and initial tristimulus color value prior to treatment. Means and standard errors in the bottom panels are adjusted for effects of cohort category and initial tristimulus color value prior to the onset of social interactions. See text for further details of the analyses. Note the difference in scale on the Y-axis of the graphs depicting change in hue. Dom, dominant; Sub, subordinate.

birds from the second capture site (data available upon request). Because our sample size was small for this experiment, we repeated the analyses with an additional 51 males included in the data set. We detected no interaction between sex and treatment, indicating that including those males was a valid means of increasing the sample size for the experiment. The results from the analyses based on females and males were qualitatively identical to those based only on females (see Supplementary Material). To test whether our inability to detect an effect of wingclipping on bill color was a result of including birds for which considerable time had lapsed between the onset of the treatment and the bill color measurement (see Effect of Energetic Stressor and Social Experience on H:L ratio, below), we used a one-way ANOVA to test for a difference in change in each tristimulus variable based only on birds recaptured 7-9 days after the initial capture ( $n=7$ clipped, 5 control). We did not include initial tristimulus value, timespan or the interaction between timespan and treatment as covariates in those analyses because of the small sample size. Those analyses similarly failed to detect an effect of treatment on any of the bill color tristimulus variables [brightness: $F_{(1,10)}=0.345, P=0.570$; saturation: $F_{(1,10)}=0.212$, $P=0.655$; hue: $\left.F_{(1,10)}=0.053, P=0.823\right]$.

In the Social Experience experiment, dominant $(n=16)$ and subordinate $(n=14)$ females differed significantly in the change in bill color over the course of social interactions when controlling for cohort and initial bill color (Table 2), with social fate affecting the change in bill brightness $(P=0.002)$ and yellow saturation $(P=0.018)$. Brightness increased in dominants and decreased in subordinates, whereas yellow saturation decreased slightly in dominants and increased in subordinates (Figure 2). The change in bill hue did not differ between dominants and subordinates $(P=0.237$; Figure 2$)$.

The mean within-individual chromatic change in bill color in response to social interactions was detectable in both dominant 
TABLE 2 | Results of generalized linear models testing for change in bill color in response to social interactions in the Social Experience Experiment.

\begin{tabular}{llccc}
\hline $\begin{array}{l}\text { Response } \\
\text { variable }\end{array}$ & Predictor variable & $\begin{array}{c}\text { Likelihood } \\
\text { ratio } \chi^{2}\end{array}$ & df & $\boldsymbol{P}$ \\
\hline Brightness & Social fate & 9.848 & 1 & 0.002 \\
& Cohort & 14.419 & 4 & 0.006 \\
& Initial brightness & 8.650 & 1 & 0.003 \\
& Intercept & 0.109 & 1 & 0.741 \\
\hline Yellow saturation & Social fate & 5.639 & 1 & 0.018 \\
& Cohort & 13.954 & 4 & 0.007 \\
& Initial saturation & 3.672 & 1 & 0.055 \\
& Intercept & 1.203 & 1 & 0.273 \\
\hline Hue & Social fate & 1.400 & 1 & 0.237 \\
& Cohort & 16.513 & 4 & 0.002 \\
& Initial hue & 2.228 & 1 & 0.135 \\
& Intercept & 11.162 & 1 & 0.001 \\
\hline
\end{tabular}

"Social fate" refers to the outcome (dominant or subordinate) of competitive interactions over a $26 \mathrm{~h}$ period.

(mean $\Delta S=7.91 \mathrm{JND}$, s.e. $=1.25, n=16$ ) and subordinate (mean $\Delta S=7.60 \mathrm{JND}$, s.e. $=1.01, n=14$ ) females. The achromatic change also was likely detectable, though to a lesser degree (dominants: mean $\Delta L=1.55$, s.e. $=0.23, n=16$; subordinates: mean $\Delta L=1.77$, s.e. $=0.31, n=14$ ). The results were similar when we used the "forest shade" illuminant in pavo (dominants: $\Delta S=6.56 \mathrm{JND}$, s.e. $=1.12 ; \Delta L=1.76 \mathrm{JND}$, s.e. $=0.26$; subordinates: $\Delta S=5.82 \mathrm{JND}$, s.e. $=0.91 ; \Delta L=1.79$, s.e. $=0.34)$.

A comparison of the magnitude of color change between the two experiments confirmed that the magnitude of change in bill brightness in the Social Experience experiment was significantly greater than that in the Energetic Stressor experiment. When controlling for initial bill brightness and timespan between measurements, treatment (clipped, unclipped, dominant, subordinate) explained a significant amount of variation in the change in brightness $\left(\chi^{2}=9.526, d f=3, P=0.023\right)$, with post-hoc analyses revealing a significant difference between dominants and subordinates $(P=0.005)$, but not between clipped and unclipped individuals $(P=0.577)$. The magnitude of change did not differ between the two experiments for yellow saturation $\left(\chi^{2}=2.719, d f=3, P=0.437\right)$ or hue $\left(\chi^{2}=3.506\right.$, $d f=3, P=0.320)$.

\section{Effect of Energetic Stressor and Social Experience on H:L Ratio}

In the Energetic Stressor experiment, birds that received the wing-clip treatment $(n=10)$ differed significantly from birds in the control treatment $(n=12)$ in the change in $\mathrm{H}: \mathrm{L}$ ratio between first and second captures, with $\mathrm{H}: \mathrm{L}$ ratio tending to increase in clipped birds and decrease in control birds (likelihood ratio $\chi^{2}=$ 13.969, $d f=1, P<0.0002$; Table 1; Figure 3) when controlling for the timespan between the two measures, the interaction between treatment and timespan, and initial H:L ratio. This result was not affected by inclusion of year as a factor or by omitting the birds captured at the second field site (data available upon request). To increase the sample size, we also ran this analysis with data from 47 additional males; that analysis yielded qualitatively identical results (see Supplementary Material). Because the interaction between treatment and timespan also was significant (Table 1), we divided the sample into birds that were recaptured 7-9 days after the initial capture (7 clipped, 5 control) and those that were recaptured 12-22 days after initial capture (3 clipped, 7 control), and used a one-way ANOVA to test for an effect of the wing-clipping treatment in each group (we did not include initial $\mathrm{H}: \mathrm{L}$ ratio, timespan, or the interaction between timespan and treatment because of the small sample size). We found a significantly higher H:L ratio in clipped birds than in control birds in the group that was recaptured 7-9 days after the initial capture $\left[F_{(1,10)}=5.92, P=0.035\right]$, but not in the group that was captured $12-22$ days after initial capture $\left[F_{(1,8)}=1.28\right.$, $P=0.290]$, indicating that the effect of the stressor may have waned over time.

In the Social Experience experiment, the $\mathrm{H}: \mathrm{L}$ ratio of dominant birds $(n=16)$ was not different from that of subordinate birds ( $n=13$; we were unable to obtain a blood smear from one subordinate bird) following social interactions (likelihood ratio $\chi^{2}<0.001, d f=1, P=0.999$; Figure 3 ). The time lapse between the onset of the experimental stimulus (wing clipping or social interactions) and measurement of the $\mathrm{H}$ :L ratio was substantially shorter in the Social Experience experiment (mean $=1.6 \mathrm{~d}$, s.e. $=0.22 \mathrm{~d}$, range $1-4 \mathrm{~d}$ ) than in the Energetic Stressor experiment $($ mean $=11.5 \mathrm{~d}$, s.e. $=1.02 \mathrm{~d}$, range $7-$ $22 \mathrm{~d}$; mean $=7.92 \mathrm{~d}$, s.e. $=0.19 \mathrm{~d}$, range $7-9 \mathrm{~d}$ in the subset for which the treatment effect was strongest). If the time lag between onset of a stressor and manifestation as an increase in H:L ratio is greater than a day or so, we may have been unable to detect an effect of social experience on $\mathrm{H}: \mathrm{L}$ ratio in cohorts $2-5$ of the experiment because we measured $\mathrm{H}$ :L ratio in those cohorts about $4 \mathrm{~h}$ after the conclusion of social trials. Therefore, we examined H:L ratio more closely within cohort 1 , which experienced a time lag of $4 \mathrm{~d}$ between the conclusion of trials and collection of a blood sample. In that cohort, we obtained blood samples from 4 dominant and 1 subordinate bird. The H:L ratios of the dominant birds ranged from 0.10 to 0.49 (mean $=0.215$, s.e. $=0.0918$ ), whereas the $\mathrm{H}: \mathrm{L}$ ratio of the single subordinate was 0.50 . A one-sample $t$-test comparing the $\mathrm{H}: \mathrm{L}$ ratio of the single subordinate bird to the mean $\mathrm{H}: \mathrm{L}$ ratio of the dominant birds indicates a marginally significant difference (one-sample $t=-3.105, d f=3, P_{2-\text { tailed }}=0.053$; Figure 3), thus providing weak evidence that the outcome of competitive interactions may have led to differences in stress-response levels in this experiment. We note that stress-response levels of newly captive birds are expected to be much higher than those of freeranging birds (Dickens et al., 2009), and therefore the observed difference in H:L ratio between our two experiments by itself is not informative (birds in social experience experiment, winners and losers combined: mean $\mathrm{H}: \mathrm{L}=0.903$, s.e. $=0.145, n=29$; birds in the Energetic Stressor experiment at their second capture when they exhibited a higher H:L ratio: mean $=0.146$, s.e. $=$ $0.019, n=22$; Mann-Whitney $U=58.0, P<0.00001)$. However, 


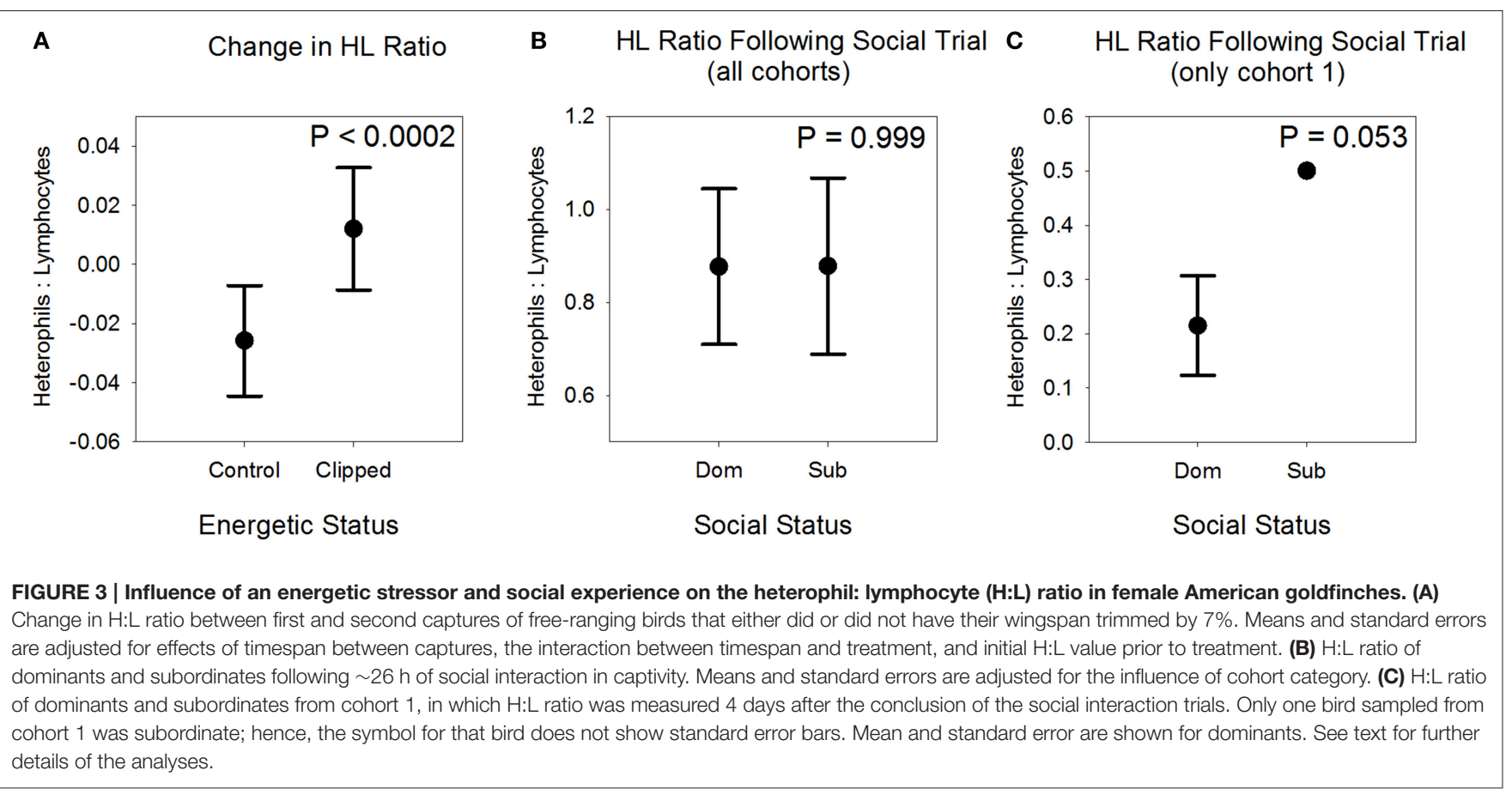

the critical issue is the difference in $\mathrm{H}: \mathrm{L}$ ratio between treatments within each experiment.

\section{DISCUSSION}

Our study provides support for the hypothesis that dynamic condition-dependent bill color change in female American goldfinches signals the outcome of prior social interactions. Furthermore, our results indicate that bill color of winners and losers of competitive social interactions changes in opposite directions, with winners becoming brighter and losers becoming more drab. Interestingly, the magnitude of color change appears similar in both groups, suggesting that bill color may reflect both winner and loser effects. These results are consistent with those of previous experiments showing that bill color of female American goldfinches functions as a signal of competitive status in interactions with other female goldfinches (Murphy et al., 2009), but does not appear to function in other social contexts (Murphy et al., 2009, 2014). In addition, our findings add to a growing body of literature showing that socially-mediated change in expression of a dynamic status signal can affect the outcome of future competitive interactions (Zuk and Johnsen, 2000; Setchell and Dixson, 2001; Gleeson, 2006; Cornwallis and Birkhead, 2008; Karubian et al., 2011; Rhodes and Schlupp, 2012; Dey et al., 2014). Taken together, these results challenge traditional models of condition-dependent signaling that assume that signals reflect, but do not influence, the physiological processes that mediate competitive ability (Rubenstein and Hauber, 2008; Tibbetts, 2014; Vitousek et al., 2014).

Our Social Experience experiment clearly demonstrates a response to social interactions that is manifested as a change in expression of bill color consistent with the social experience signaling hypothesis. Although the color changes we observed were subtle (the difference in bill brightness between dominants and subordinates increased by $2 \%$ ), the dynamic fluctuation in color represents roughly $15 \%$ of the range of bill brightness observed in our experiment (minimum observed \% reflectance $=23.7$; maximum $=36.9$ ). Moreover, the magnitude of the chromatic changes that we observed in both winners and losers were sufficiently large to be easily detectable by goldfinch receivers. The changes in the achromatic component of bill color were less intense, and were likely on the edge of detectability by receivers. Additionally, the females in our Social Experience experiment exhibited substantial stress-response that was likely due to captivity (Dickens and Romero, 2009; Dickens et al., 2009; Rosenthal et al., 2012), and this background stress-response may have limited the magnitude of their potential responses to social stressors relative to changes that occur under more natural conditions. Interestingly, we note that while both this study and our other study of short-term bill color change in female goldfinches (Rosenthal et al., 2012) found that bill brightness decreased while yellow saturation increased in response to perturbation, our previous studies of "snapshot" measures of bill color have revealed positive correlations between current yellow saturation and current indices of condition (Kelly et al., 2012; Pham et al., 2014). At present we do not clearly understand the mechanisms of bill coloration in goldfinches, but these patterns suggest that in addition to carotenoids, bill color is likely affected by other mechanisms such as hemoglobin, and that short- and longer-term changes may involve somewhat different mechanisms (see Rosenthal et al., 2012 for a fuller discussion of this issue). Moreover, these patterns suggest that different components of bill color may reflect condition on different time scales. 
In contrast to results from our Social Experience experiment, we found no effect of energetic stress associated with elevated flight costs on bill color, even though our wing-clip treatment significantly elevated stress-response levels of goldfinches. The sample size for our Energetic Stressor experiment was moderate (22-23 females, depending on the analysis), but the inclusion of an additional 47-51 males in those analyses yielded far greater power and yet results were qualitatively identical, suggesting that our inability to detect an effect of wing-clipping on bill color change among females is not simply due to small sample size. Taken together, the social experience and energetic stressor experiments reported here suggest that at least some components of bill color change are more sensitive to the outcome of competitive social interactions than to a non-social stressor such as an increase in general energy demands.

We note that two earlier studies demonstrated short-term changes in bill color in captive goldfinches that were not subjected to social defeat (Rosen and Tarvin, 2006; Rosenthal et al., 2012). Likewise, studies of seasonal development of bill color that measured changes in captive birds over a span of 46 weeks demonstrate that the seasonal development of colorful bills in male goldfinches is influenced by diet and gut parasites (McGraw and Hill, 2000; Hill et al., 2009). Hence, bill color change responds to at least some kinds of perturbations other than social interactions. We find it compelling, however, that this signal is modified by competitive experience, but not modified by all forms of non-social stressors, which suggests that the signal primarily reflects information that is relevant to the signaling context. Future research should investigate whether female goldfinch bill color, which functions as a status signal (Murphy et al., 2009), best reflects those stressors that have the greatest impact on an individual's ability to invest in competitive interactions.

We also note that in the earlier studies of short-term bill color change in goldfinches, birds were kept in individual cages from which they could see and hear finches in adjacent cages, but could not physically interact (i.e., bill fence, chase, supplant) with them. Such conditions may have represented adverse social conditions that interfered with the normal social feedback that goldfinches would experience when foraging in groups in the wild, and therefore it is possible that they could have represented a form of social stressor similar to that resulting from separation anxiety, which has been demonstrated in other species (Kikusui et al., 2006). Thus, in the earlier goldfinch studies social stressors could have contributed to bill color change, even as bill color change was exacerbated by other sources of stress such as immune system activation (Rosenthal et al., 2012). Importantly, the Social Experience hypothesis would be supported even if goldfinch bill color change is indeed sensitive to moderate levels of non-social energetic stressors, if individuals compensate for the energetic "drain" on bill color by shunting those costs to other physiological processes so that elevated bill color can be maintained. Future experiments should attempt to tease apart these alternative explanations.

Although our study suggests that female goldfinch bill color change may be more sensitive to social experience than to a non-social energetic stressor, the time lag between the onset of our experimental stressors and our measurements of their effects differed between the two experiments, raising the possibility that our manipulation of energetic stress induced a change in bill color which we did not detect because we measured color too late after the onset of the stressor. This is unlikely to be the case for two reasons: (1) we did not detect an effect of wing clipping on bill color even in those individuals measured only 7-9 days following the administration of the treatment when the H:L ratio measures indicated the birds were stressed in response to the treatment (see Supplemental Material); (2) in an earlier experiment we found that bill color declined continuously for at least 4 days and then remained depressed for at least two more days after bringing goldfinches into captivity, with no indication of abatement prior to their release at the end of the experiment (Rosenthal et al., 2012), suggesting that bill color remains dampened for the duration that a chronic stressor is applied. Another alternative explanation for our results is that the difference in response of bill color to stressors in the two experiments stemmed from a difference in the magnitude of the stressor, as opposed to the kind of stressor, imposed by the treatments. However, although birds in our Social Experience experiment appeared to be more stressed than those in the Energetic Stress experiment based on $\mathrm{H}: \mathrm{L}$ ratios, the critical comparison is the difference in stress-response level between treatments within an experiment. Although both dominant and subordinate individuals appeared to be highly stressed by the time we measured $\mathrm{H}: \mathrm{L}$ ratios, the difference in $\mathrm{H}: \mathrm{L}$ ratio between them following the experiment was small relative to the difference between treatments in the Energetic Stressor experiment. This suggests that if the significant difference in bill color change between winners and losers truly resulted from a difference in stress per se, we should have seen a much greater difference in bill color change in the Energetic Stressor experiment. Moreover, we suspect the energetic stress induced by our wing clipping treatment was substantial, as other studies have detected significant effects on life history allocation in response to smaller increases in flight costs than those imposed in our study. For example, Tieleman et al. (2008) found that tropical house wrens (Troglodytes aedon) that had flight costs elevated by an estimated $7.5 \%$ provisioned their broods $23-31 \%$ less frequently than control birds. Therefore, it seems our manipulation of goldfinch flight costs by almost $20 \%$ is likely to have imposed important constraints on energetic balance.

Our results suggest that goldfinch receivers may be able to assess the recent social experience of potential competitors based on the dynamics of their bill color expression. Female goldfinches avoid competitive interactions with other females that express colorful bills (Murphy et al., 2009), so the fact that bill color changes in response to competitive interactions means that the outcome of those interactions may potentially influence the outcome of future interactions, which could lead to winner-loser effects-the phenomenon in which winners of social contests experience a higher probability of winning future contests while losers experience a lower probability, independent of their respective intrinsic resource holding power (e.g., Landau, 1951a,b; Hsu et al., 2006, 2009; Hock and Huber, 2009; Fawcett and Johnstone, 2010; Fuxjager and Marler, 2010; Dugatkin 
and Reeve, 2014). Because both winners and losers stand to benefit from reliable information about the likelihood that losers will challenge winners in future contests, a signaling system that provides such information could evolve in species that live in stable groups in which individuals directly compete for resources. American goldfinches live in loose flocks in which individuals forage closely together in concentrated but spatially and temporally ephemeral food patches. Individuals within captive flocks of goldfinches appear to discriminate the relative dominance ranks of competitors at feeders by visual inspection and thereby avoid competing with more dominant individuals (Popp, 1987), and they appear to exhibit winnerloser effects (Popp, 1988), although both of those studies were conducted during winter when goldfinch bills were brown instead of orange. Whether flock composition of free-ranging goldfinches during the breeding season (when colorful bills are expressed) is stable enough to provide benefits from signals of winner-loser effects remains unstudied. Social network analysis in relation to the social experience signaling system could shed much light on the implications of bill color change for fitness in goldfinches.

Recent work has suggested that if both signal expression and competitive status are dynamic and hormonally mediated, social feedback during competitive interactions may lead to alteration of both signal expression and competitive ability (Rubenstein and Hauber, 2008; Dey et al., 2014; Tibbetts, 2014), yielding a signaling system in which signal expression and competitive status covary and simultaneously affect each other. Dynamic condition-dependent ornament expression of several bird species, including female goldfinches, appears to be correlated with circulating testosterone and/or corticosterone (Eens et al., 2000; McGraw, 2006; Ardia et al., 2010; McGraw et al., 2011; Pham et al., 2014). Circulating levels of each of these hormones can be affected by social interactions (Goymann et al., 2007; Safran et al., 2008; but see Rosvall et al., 2014), providing a feedback mechanism by which hormonal state influences ornament expression, ornament expression influences the nature and outcome of social interactions, and social interactions influence hormonal state (Rubenstein and Hauber, 2008; Maia et al., 2012; Leary and Knapp, 2014; Vitousek et al., 2014). Although "snapshot" measures of bill color of female goldfinches appear to correlate with circulating testosterone levels (Pham et al., 2014), experiments in which hormone levels are manipulated will be necessary to confirm whether rapid bill color change is hormonally mediated in goldfinches as it is in

\section{REFERENCES}

Ardia, D. R., Broughton, D. R., and Gleicher, M. J. (2010). Short-term exposure to testosterone propionate leads to rapid bill color and dominance changes in zebra finches. Horm. Behav. 58, 526-532. doi: 10.1016/j.yhbeh.2010.04.004

Armario, A., Daviu, N., Munoz-Abellan, C., Rabasa, C., Fuentes, S., Belda, X., et al. (2012). What can we know from pituitary-adrenal hormones about the nature and consequences of exposure to emotional stressors? Cell. Mol. Neurobiol. 32, 749-758. doi: 10.1007/s10571-012-9814-6 other species (Eens et al., 2000; McGraw, 2006; Ardia et al., 2010; McGraw et al., 2011).

In sum, our study provides evidence that the dynamic component of bill color of female goldfinches reflects the outcome of recent competitive interactions, but appears to be less sensitive to a more general non-social stressor such as that stemming from elevated flight costs (this study) or from stressors such as current blood parasite infection (Lumpkin et al., 2014). A signaling system such as this, in which a dynamic signal influences the outcome of social interactions and social interactions in turn rapidly influence signal expression, exemplifies a level of complexity that is not present in communication systems based on relatively static conditiondependent signals.

\section{AUTHOR CONTRIBUTIONS}

KT designed the study with contributions from TM. KT, LW, DL, GS, DD, SM, and PR conducted the field and captivity work. LW, DL, GS, DD, SM, and PR conducted lab work. KT performed statistical analysis of the data. KT wrote the manuscript with major contributions from TM, and additional contributions from LW, DL, GS, DD, SM, and PR.

\section{FUNDING}

This project was funded by Oberlin College, the Jakus fund of the Oberlin College Biology Department, the A. W. Mellon Foundation, and a Research Status appointment to KT from Oberlin College. TM was supported by a Trinity University Faculty Development Grant. Funding for Open Access publication was provided by the Oberlin College Library.

\section{ACKNOWLEDGMENTS}

We are grateful to Hannah Harris for help with field and lab work, to the Lorain County Metro Parks for allowing us to work on their properties, to Marilyn Spalding for initial help with identification of white blood cell types, and to Rafael Maia for help with pavo.

\section{SUPPLEMENTARY MATERIAL}

The Supplementary Material for this article can be found online at: http://journal.frontiersin.org/article/10.3389/fevo. 2016.00079 avian facial flushing and skin colouration with agonistic interaction outcomes. Ethology 116, 1163-1170. doi: 10.1111/j.1439-0310.2010.01834.x

Baumhardt, P. E., Moore, B. A., Doppler, M., and Fernandez-Juricic, E. (2014). Do American goldfinches see their world like passive prey foragers? A study on visual fields, retinal topography, and sensitivity of photoreceptors. Brain Behav. Evol. 83, 181-198. doi: 10.1159/000357750

Buchanan, K. L. (2000). Stress and the evolution of condition-dependent signals. Trends Ecol. Evol. 15, 156-160. doi: 10.1016/S0169-5347(99)01812-1 
Buwalda, B., Kole, M. H. P., Veenema, A. H., Huininga, M., de Boer, S. F., Korte, S. M., et al. (2005). Long-term effects of social stress on brain and behavior: a focus on hippocampal functioning. Neurosci. Biobehav. Rev. 29, 83-97. doi: 10.1016/j.neubiorev.2004.05.005

Carere, C., Groothuis, T. G. G., Mostl, E., Daan, S., and Koolhaas, J. M. (2003). Fecal corticosteroids in a territorial bird selected for different personalities: daily rhythm and the response to social stress. Horm. Behav. 43, 540-548. doi: 10.1016/S0018-506X(03)00065-5

Carere, C., Welink, D., Drent, P. J., Koolhaas, J. M., and Groothuis, T. G. G. (2001). Effect of social defeat in a territorial bird (Parus major) selected for different coping styles. Physiol. Behav. 73, 427-433. doi: 10.1016/S0031-9384(01)00492-9

Carrascal, L. M., and Polo, V. (2006). Effects of wing area reduction on winter body mass and foraging behaviour in coal tits: field and aviary experiments. Anim. Behav. 72, 663-672. doi: 10.1016/j.anbehav.2005.11.027

Cornwallis, C. K., and Birkhead, T. R. (2008). Plasticity in reproductive phenotypes reveals status-specific correlations between behavioral, morphological, and physiological sexual traits. Evolution 62, 1149-1161. doi: 10.1111/j.15585646.2008.00346.x

Coutlee, E. L. (1967). Agonistic behavior in the American goldfinch. Wilson Bull. 79,89

Creel, S., Dantzer, B., Goymann, W., and Rubenstein, D. R. (2013). The ecology of stress: effects of the social environment. Funct. Ecol. 27, 66-80. doi: 10.1111/j.1365-2435.2012.02029.x

Davis, A. K., Maney, D. L., and Maerz, J. C. (2008). The use of leukocyte profiles to measure stress in vertebrates: a review for ecologists. Funct. Ecol. 22, 760-772. doi: 10.1111/j.1365-2435.2008.01467.x

Dey, C. J., Dale, J., and Quinn, J. S. (2014). Manipulating the appearance of a badge of status causes changes in true badge expression. Proc. R. Soc. B Biol. Sci. 281, 20132680. doi: 10.1098/rspb.2013.2680

Dickens, M. J., Earle, K. A., and Romero, L. M. (2009). Initial transference of wild birds to captivity alters stress physiology. Gen. Comp. Endocrinol. 160, 76-83. doi: 10.1016/j.ygcen.2008.10.023

Dickens, M. J., and Romero, L. M. (2009). Wild European Starlings (Sturnus vulgaris) adjust to captivity with sustained sympathetic nervous system drive and a reduced fight-or-flight response. Physiol. Biochem. Zool. 82, 603-610. doi: $10.1086 / 603633$

Dugatkin, L. A., and Reeve, H. K. (2014). Winning, losing, and reaching out. Behav. Ecol. 25, 675-679. doi: 10.1093/beheco/aru078

Eens, M., Van Duyse, E., Berghman, L., and Pinxten, R. (2000). Shield characteristics are testosterone-dependent in both male and female moorhens. Horm. Behav. 37, 126-134. doi: 10.1006/hbeh.1999.1569

Faivre, B., Gregoire, A., Preault, M., Cezilly, F., and Sorci, G. (2003). Immune activation rapidly mirrored in a secondary sexual trait. Science 300, 103-103. doi: $10.1126 /$ science. 1081802

Fawcett, T. W., and Johnstone, R. A. (2010). Learning your own strength: winner and loser effects should change with age and experience. Proc. R. Soc. B Biol. Sci. 277, 1427-1434. doi: 10.1098/rspb.2009.2088

Fuxjager, M. J., and Marler, C. A. (2010). How and why the winner effect forms: influences of contest environment and species differences. Behav. Ecol. 21, 37-45. doi: 10.1093/beheco/arp148

Gleeson, D. J. (2006). Context-dependent effect of social environment on immune response and sexual signalling in male zebra finches. Aust. J. Zool. 54, 375-379. doi: 10.1071/ZO06001

Goymann, W., Landys, M. M., and Wingfield, J. C. (2007). Distinguishing seasonal androgen responses from male-male androgen responsiveness-revisiting the challenge hypothesis. Horm. Behav. 51, 463-476. doi: 10.1016/j.yhbeh.2007.01.007

Hawley, D. M. (2006). Asymmetric effects of experimental manipulations of social status on individual immune response. Anim. Behav. 71, 1431-1438. doi: 10.1016/j.anbehav.2005.12.004

Hawley, D. M., Lindstrom, K., and Wikelski, M. (2006). Experimentally increased social competition compromises humoral immune responses in house finches. Horm. Behav. 49, 417-424. doi: 10.1016/j.yhbeh.2005.09.003

Hill, G. E. (2011). Condition-dependent traits as signals of the functionality of vital cellular processes. Ecol. Lett. 14, 625-634. doi: 10.1111/j.14610248.2011.01622.x

Hill, G. E. (2014). Cellular respiration: the nexus of stress, condition, and ornamentation. Integr. Comp. Biol. 54, 645-657. doi: 10.1093/icb/icu029
Hill, G. E., Hood, W. R., and Huggins, K. (2009). A multifactorial test of the effects of carotenoid access, food intake and parasite load on the production of ornamental feathers and bill coloration in American goldfinches. J. Exp. Biol. 212, 1225-1233. doi: 10.1242/jeb.026963

Hock, K., and Huber, R. (2009). Models of winner and loser effects: a cost-benefit analysis. Behaviour 146, 69-87. doi: 10.1163/156853908X390931

Hostetler, C. M., and Ryabinin, A. E. (2013). The CRF system and social behavior: a review. Front. Neurosci. 7:92. doi: 10.3389/fnins.2013.00092

Hsu, Y. I., Lee, and Lu, C. (2009). Prior contest information: mechanisms underlying winner and loser effects. Behav. Ecol. Sociobiol. 63, 1247-1257. doi: 10.1007/s00265-009-0791-9

Hsu, Y. Y., Earley, R. L., and Wolf, L. L. (2006). Modulation of aggressive behaviour by fighting experience: mechanisms and contest outcomes. Biol. Rev. 81, 33-74. doi: $10.1017 /$ S146479310500686X

Karubian, J., Lindsay, W. R., Schwabl, H., and Webster, M. S. (2011). Bill coloration, a flexible signal in a tropical passerine bird, is regulated by social environment and androgens. Anim. Behav. 81, 795-800. doi: 10.1016/j.anbehav.2011.01.012

Kelly, R. J., Murphy, T. G., Tarvin, K. A., and Burness, G. (2012). Carotenoidbased ornaments of female and male American goldfinches (Spinus tristis) show sex-specific correlations with immune function and metabolic rate. Physiol. Biochem. Zool. 85, 348-363. doi: 10.1086/666059

Kikusui, T., Winslow, J. T., and Mori, Y. (2006). Social buffering: relief from stress and anxiety. Philos. Trans. R. Soc. B Biol. Sci. 361, 2215-2228. doi: 10.1098/rstb.2006.1941

Landau, H. G. (1951a). On dominance relations and the structure of animal societies: I. effects of inherent characteristics. Bull. Math. Biophys. 13, 1-19. doi: 10.1007/BF02478336

Landau, H. G. (1951b). On dominance relations and the structure of animal societies II. some effects of possible social causes. Bull. Math. Biophy. 13, 245-262. doi: 10.1007/BF02477920

Leary, C. J., and Knapp, R. (2014). The stress of elaborate male traits: integrating glucocorticoids with androgen-based models of sexual selection. Anim. Behav. 89, 85-92. doi: 10.1016/j.anbehav.2013.12.017

Lumpkin, D. C., Murphy, T. G., and Tarvin, K. A. (2014). Blood parasite infection differentially relates to carotenoid-based plumage and bill color in the American goldfinch. Ecol. Evol. 4, 3210-3217. doi: 10.1002/ece3.1164

Lyon, B. E., and Montgomerie, R. (2012). Sexual selection is a form of social selection. Philos. Trans. R. Soc. B Biol. Sci. 367, 2266-2273. doi: 10.1098/rstb.2012.0012

Maia, R., Brasileiro, L., Lacava, R. V., and Macedo, R. H. (2012). Social environment affects acquisition and color of structural nuptial plumage in a sexually dimorphic tropical passerine. PLoS ONE 7:e47501. doi: 10.1371/journal.pone.0047501

Maia, R., Eliason, C. M., Bitton, P., Doucet, S. M., and Shawkey, M. D. (2013). pavo: an $\mathrm{R}$ package for the analysis, visualization and organization of spectral data. Methods Ecol. Evol. 4, 906-913. doi: 10.1111/2041-210x. 12069

Mauck, R. A., and Grubb, T. C. (1995). Petrel parents shunt all experimentally increased reproductive costs to their offspring. Anim. Behav. 49, 999-1008. doi: 10.1006/anbe.1995.0129

McGraw, K. J. (2006). Sex steroid dependence of carotenoid-based coloration in female zebra finches. Physiol. Behav. 88, 347-352. doi: 10.1016/j.physbeh.2006.04.003

McGraw, K. J., and Hill, G. E. (2000). Differential effects of endoparasitism on the expression of carotenoid- and melanin-based ornamental coloration. Proc. R. Soc. Lond. Ser. B Biol. Sci. 267, 1525-1531. doi: 10.1098/rspb.20 00.1174

McGraw, K. J., and Hill, G. E. (2001). Carotenoid access and intraspecific variation in plumage pigmentation in male American goldfinches (Carduelis tristis) and northern cardinals (Cardinals cardinalis). Funct. Ecol. 15, 732-739. doi: 10.1046/j.0269-8463.2001.00574.x

McGraw, K. J., Lee, K., and Lewin, A. (2011). The effect of capture-and-handling stress on carotenoid-based beak coloration in zebra finches. J. Comp. Physiol. A Neuroethol. Sens. Neural Behav. Physiol. 197, 683-691. doi: 10.1007/s00359011-0631-z

Montgomerie, R. (2008a). CLR, Version 1.05. Ontario: Kingston.

Montgomerie, R. (2008b). RCLR, Version 0.9.28. Ontario: Kingston. 
Mundinger, P. C. (1972). Annual testicular cycle and bill color change in the eastern American goldfinch. Auk 89, 403-419. doi: 10.2307/4084214

Murphy, T. G., Rosenthal, M. F., Montgomerie, R., and Tarvin, K. A. (2009). Female American goldfinches use carotenoid-based bill coloration to signal status. Behav. Ecol. 20, 1348-1355. doi: 10.1093/beheco/arp140

Murphy, T. G., West, J. A., Pham, T. T., Cevallos, L. M., Simpson, R. K., and Tarvin, K. A. (2014). Same trait, different receiver response: unlike females, male American goldfinches do not signal status with bill colour. Anim. Behav. 93, 121-127. doi: 10.1016/j.anbehav.2014.04.034

Navarro, C., Perez-Contreras, T., Aviles, J. M., McGraw, K. J., and Soler, J. J. (2010). Beak colour reflects circulating carotenoid and vitamin A levels in spotless starlings (Sturnus unicolor). Behav. Ecol. Sociobiol. 64, 1057-1067. doi: 10.1007/s00265-010-0920-5

Pennycuick, C. J. (2008a). Modelling the Flying Bird. Burlington, MA: Elsevier; Academic Press.

Pennycuick, C. J. (2008b). Flight for Windows, v 1.24; Available online at: http://www.bio.bristol.ac.uk/people/pennycuick.htm

Pérez-Rodriguez, L. (2008). Carotenoid-based ornamentation as a dynamic but consistent individual trait. Behav. Ecol. Sociobiol. 62, 995-1005. doi: $10.1007 / \mathrm{s} 00265-007-0527-7$

Pham, T. T., Queller, P. S., Tarvin, K. A., and Murphy, T. G. (2014). Honesty of a dynamic female aggressive status signal: baseline testosterone relates to bill color in female American goldfinches. J. Avian Biol. 45, 22-28. doi: 10.1111/j.1600-048X.2013.00286.x

Popp, J. W. (1987). Choice of opponents during competition for food among American goldfinches. Ethology 75, 31-36. doi: 10.1111/j.14390310.1987.tb00640.x

Popp, J. W. (1988). Effects of experience on agonistic behavior among American goldfinches. Behav. Processes 16, 11-19. doi: 10.1016/0376-6357(88)90014-9

Rhodes, S. B., and Schlupp, I. (2012). Rapid and socially induced change of a badge of status. J. Fish Biol. 80, 722-727. doi: 10.1111/j.1095-8649.2011.03212.x

Rohwer, S. (1975). The social significance of avian winter plumage variability. Evolution 29, 593-610. doi: 10.2307/2407071

Rosen, R. F., and Tarvin, K. A. (2006). Sexual signals of the male American goldfinch. Ethology 112, 1008-1019. doi: 10.1111/j.1439-0310.2006.01257.x

Rosenthal, M. F., Murphy, T. G., Darling, N., and Tarvin, K. A. (2012). Ornamental bill color rapidly signals changing condition. J. Avian Biol. 43, 553-564. doi: 10.1111/j.1600-048X.2012.05774.x

Rosvall, K. A., Peterson, M. P., Reichard, D. G., and Ketterson, E. D. (2014). Highly context-specific activation of the HPG axis in the dark-eyed junco and implications for the challenge hypothesis. Gen. Comp. Endocrinol. 201, 65-73. doi: 10.1016/j.ygcen.2014.03.026

Rubenstein, D. R., and Hauber, M. E. (2008). Dynamic feedback between phenotype and physiology in sexually selected traits. Trends Ecol. Evol. 23, 655-658. doi: 10.1016/j.tree.2008.07.010

Rutte, C., Taborsky, M., and Brinkhof, M. W. G. (2006). What sets the odds of winning and losing? Trends Ecol. Evol. 21, 16-21. doi: 10.1016/j.tree.2005.10.014

Safran, R. J., Adelman, J. S., McGraw, K. J., and Hau, M. (2008). Sexual signal exaggeration affects physiological state in male barn swallows. Curr. Biol. 18, R461-R462. doi: 10.1016/j.cub.2008.03.031

Schulte, P. M. (2014). What is environmental stress? Insights from fish living in a variable environment. J. Exp. Biol. 217, 23-34. doi: 10.1242/jeb.089722
Setchell, J. M., and Dixson, A. F. (2001). Changes in the secondary sexual adornments of male mandrills (Mandrillus sphinx) are associated with gain and loss of alpha status. Horm. Behav. 39, 177-184. doi: 10.1006/hbeh.20 00.1628

Siddiqi, A., Cronin, T. W., Loew, E. R., Vorobyev, M., and Summers, K. (2004). Interspecific and intraspecific views of color signals in the strawberry poison frog Dendrobates pumilio. J. Exp. Biol. 207, 2471-2485. doi: 10.1242/jeb. 01047

Sullivan, M. S. (1994a). Discrimination among males by female zebra finches based on past as well as current phenotype. Ethology 96, 97-104. doi: 10.1111/j.14390310.1994.tb00885.x

Sullivan, M. S. (1994b). Mate choice as an information gathering process under time constraint - implications for behavior and signal-design. Anim. Behav. 47, 141-151. doi: 10.1006/anbe.1994.1016

Tibbetts, E. A. (2014). The evolution of honest communication: integrating social and physiological costs of ornamentation. Integr. Comp. Biol. 54, 578-590. doi: 10.1093/icb/icu083

Tieleman, B. I., Dijkstra, T. H., Klasing, K. C., Visser, G. H., and Williams, J. B. (2008). Effects of experimentally increased costs of activity during reproduction on parental investment and self-maintenance in tropical house wrens. Behav. Ecol. 19, 949-959. doi: 10.1093/beheco/arn051

Torres, R., and Velando, A. (2003). A dynamic trait affects continuous pair assessment in the blue-footed booby, Sula nebouxii. Behav. Ecol. Sociobiol. 55, 65-72. doi: 10.1007/s00265-003-0669-1

Velando, A., Beamonte-Barrientos, R., and Torres, R. (2006). Pigment-based skin colour in the blue-footed booby: an honest signal of current condition used by females to adjust reproductive investment. Oecologia 149, 535-542. doi: 10.1007/s00442-006-0457-5

Vitousek, M. N., Zonana, D. M., and Safran, R. J. (2014). An integrative view of the signaling phenotype: dynamic links between signals, physiology, behavior and social context. Curr. Zool. 60, 739-754. doi: 10.1093/czoolo/ 60.6.739

Vorobyev, M., Osorio, D., Bennett, A. T. D., Marshall, N. J., and Cuthill, I. C. (1998). Tetrachromacy, oil droplets and bird plumage colours. J. Comp. Physiol. A Neuroethol. Sens. Neural Behav. Physiol. 183, 621-633. doi: $10.1007 / \mathrm{s} 003590050286$

Wingfield, J. C. (2013). Ecological processes and the ecology of stress: the impacts of abiotic environmental factors. Funct. Ecol. 27, 37-44. doi: 10.1111/13652435.12039

Zuk, M., and Johnsen, T. S. (2000). Social environment and immunity in male red jungle fowl. Behav. Ecol. 11, 146-153. doi: 10.1093/beheco/11.2.146

Conflict of Interest Statement: The authors declare that the research was conducted in the absence of any commercial or financial relationships that could be construed as a potential conflict of interest.

Copyright (C) 2016 Tarvin, Wong, Lumpkin, Schroeder, D'Andrea, Meade, Rivers and Murphy. This is an open-access article distributed under the terms of the Creative Commons Attribution License (CC BY). The use, distribution or reproduction in other forums is permitted, provided the original author(s) or licensor are credited and that the original publication in this journal is cited, in accordance with accepted academic practice. No use, distribution or reproduction is permitted which does not comply with these terms. 